\title{
Knowledge and Awareness on the Effects of Radiation Emitted from Electronic Gadgets During Pregnancy Among Women
}

\author{
Amirtha Varshini ${ }^{1}$, and R.V. Geetha ${ }^{2}$ \\ ${ }^{1}$ S1Saveetha Dental college and Hospitals, Saveetha Institute of \\ Medical and Technical Sciences, Saveetha University, Chennai, India. \\ ${ }^{2}$ Associate Professor, Department of Microbiology, Saveetha Dental college and Hospitals, \\ Saveetha Institute of Medical and Technical Sciences, Saveetha University, Chennai, India.
}

\begin{abstract}
A pregnant woman is exposed to so many environmental influences that it may be tough to pinpoint just one that may affect her pregnancy. In today's technology driven world, everyone relies on their cell phone to stay in touch with friends and family, get their work done, keep track of what's going on around them.Widespread concerns have been raised about exposure to electromagnetic fields from sources used for mobile telecommunication. Indeed, mobile phone use has increased considerably along with reducing its costs, and developing countries are establishing mobile telecommunications rather than the more expensive fixed-line systems. Exposure to radio frequency electromagnetic field (RF-EMF) during pregnancy could affect the growth and development of the foetus and the duration of pregnancy , either directly due to radiation of the foetus and placenta or indirectly as a result of altered maternal physiology. A questionnaire based survey was conducted among 100 women to analyse their awareness, exposure time on gadgets etc and the results were analysed. Most of the women are not aware of the effects of radiation, the amount of radiation they are exposed to and also specific absorption rate (SAR) value. Women need more awareness about the usage of gadgets, time limits, radiation etc which can be achieved through health education.The aim of the study is to create awareness on the effects of radiation emitted from electronic gadgets during pregnancy among women.
\end{abstract}

KEY WORDS: RADIATION, GADGETS, PREGNANCY, EFFECTS. SAR VALUE, RF-EMF.

\section{INTRODUCTION}

We often forget that pregnancy is a wellness and not an illness. Though it is a blessing for all the expecting couples, it brings along a set of concerns and problems. A pregnant woman is exposed to various environmental hazards which may be tough to pinpoint just one that

\section{ARTICLE INFORMATION}

*Corresponding Author: geetha@saveetha.com

Received 29th July 2020 Accepted after revision 22nd Sep 2020

Print ISSN: 0974-6455 Online ISSN: 2321-4007 CODEN: BBRCBA

Thomson Reuters ISI Web of Science Clarivate Analytics USA and Crossref Indexed Journal

\section{Clarivate
Analytics}

NAAS Journal Score 2020 (4.31) SJIF: 2020 (7.728)

A Society of Science and Nature Publication,

Bhopal India 2020. All rights reserved.

Online Contents Available at: http//www.bbrc.in/

Doi: $h t t p: / / d x$.doi.org/10.21786/bbrc/13.8/116 may affect her pregnancy. In today's technology driven world, everyone relies on their cell phone to stay in touch with friends and family, get their work done, keep track of what's going on around them. In current era the digital world has expanded far beyond the desktop, and consumers now have the choice to choose from an array of devices that will satisfy their need for "anytime, anywhere" access gather information on news, family, friends and entertainment (Smith, 2010). Ionizing radiation, which includes particles (alpha and beta particles) and some electromagnetic radiation (gamma rays and $\mathrm{x}$-rays), can directly and indirectly alter the normal structure of a living cell. Non Ionizing radiation commonly interacts with tissue through the generation of heat (Brent, 1999) .Widespread concerns have been raised about exposure to electromagnetic field (EMF) from sources used for mobile telecommunication (Repacholi, 2001; Toropainen, 2003; Divan et al., 2008).

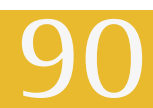


Indeed, mobile phone use has increased considerably along with reducing its costs, and developing countries are establishing mobile telecommunications rather than the more expensive fixed-line systems. The health effect of EMF on pregnancy has remained controversial despite efforts to reach consensus (Li et al., 2002).Cell phones generate radio frequency- electromagnetic fields resulting in local exposure of the human body to RFEMF. During pregnancy, the embryo and foetus are very sensitive to radiation. While in the pre implantation period, high radiation exposure may cause the death of the embryo. Exposure to RF-EMF during pregnancy could affect the growth and development of the foetus and the duration of pregnancy, either directly due to radiation of the foetus and placenta or indirectly as a result of altered maternal physiology (Tsarna et al., 2019).Several international researchers have also found that radiation exposure during pregnancy is one of the causes of autism in children. The recently concluded Danish study on the adverse effects of exposure to radiations during pregnancy resulting from cell phone usage,on the development of children found that there is greater incidence of psychiatric disorders like behavioural difficulties such as emotional and hyperactivity problems, in the children of mothers exposed to radio frequency radiations.

Some studies in rats or mice have shown that extended RF-EMF exposure in pregnant dams was linked to hyperactivity, altered neurons, or impaired cognition in offspring (Aldad et al., 2012; Haghani, Shabani and Moazzami, 2013; Zhang et al., 2015). Also there is scientific support that maternal prenatal exposure can have an effect on the development of the unborn child and also in animal studies. The most used gadgets are cell phones as it is the most personal device ever and incidentally,a mini microwave that you are carrying around, then a WiFi after all is a mini cell tower and they are hardly switched off. Every mobile phone is rated according to the level of radiation that it gives out. This rating is called the specific absorption rate (SAR) value. The SAR value gives the maximum amount of radiation, or energy, that is absorbed by the body while using the phone. The laptop on its underside has a very high EMF exposure at point of contact and heavy proximities which can be harmful for adult fertility.

\section{MATERIAL AND METHODS}

This was a cross-sectional survey study done to assess the knowledge and awareness level on the effects of radiation emitted from electronic gadgets during pregnancy. The sample size of 100 was used for this study. A self structured questionnaire with 15 questions was developed and circulated among 100 women to analyse their awareness level. The questionnaire contained time of exposure to gadgets, marital status, effects of radiation etc. The results were statistically analysed based on the charts obtained from results.

\section{RESULTS AND DISCUSSION}

The knowledge and awareness on the effects of radiation emitted from electronic gadgets during pregnancy among women were assessed. On analysing the data, most of them are working women so they have more chances of using gadgets like laptops. 96\% of the women are exposed to gadgets like cell phones, laptop, tablet (Fig.1). The vast increase of satellite and earth telecommunication, broadcasting systems, cell phones, and other telecommunication systems have exposed houses, workplaces and promenades to radiations caused from electromagnetic signals (Abad et al., 2016). On assessing the time spent on gadgets each day, $66 \%$ of the women spend more than 3 hours on their gadgets and $31 \%$ of them spend 1-2 hours per day(Fig.2). About 79\% of the women have WiFi connection in their home or work place(Fig.3). Cell phones are the most used gadget among most of the women(Fig.4). Wireless Local Area Network (WLAN) protocols are an increasing alternative to wired data networks in workplaces.

Figure 1: Bar graph representing the responses of women exposed to gadgets.

\section{EXPOSURE TO GADGETS}

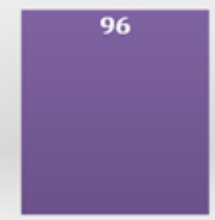

EXPOSED TO GADGETS NOT EXPOSED TO GADGETS

Figure 2: Bar graph representing the responses for time spent on gadgets each day.

\section{TIME SPENT ON GADGETS}

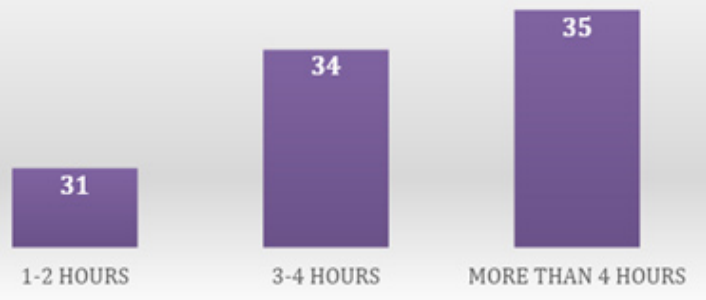

Figure 3: Bar graph representing the responses for availability of Wifi connection in their home/work place.

\section{WIFI CONNECTION}

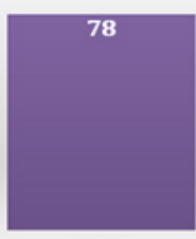

YES

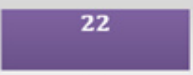

NO 
Figure 4: Bar graph representing the responses for most used gadget.

\section{MOST USED GADGET}

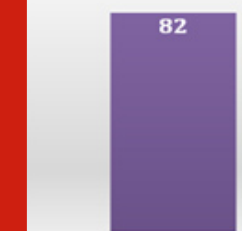

CELL PHONES

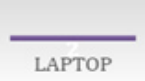

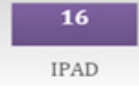

Access points in houses, public places, schools and hospitals provide signals for this communication service, known as wireless fidelity (WiFi). As happened previously with other electromagnetic-field (EMF) sources, the fast increase in WLAN use raised public concern regarding possible health effects (Sambucci et al., 2010). The point of adding WiFi as a criteria is because WiFi routers emit a lot of radiation and in fact it is a mini tower. When it comes to device for personal communication, the cell phone remains the "gadget of choice". 63\% of the women seem to be aware of the amount of radiation they are exposed to and 37\% of the women are not aware(Fig.5). Most of the women seem to be aware of the fact that it is harmful to use gadgets during pregnancy. They were asked about the harmful effects. They are growth retardation in foetus, impaired brain function, hyperactivity etc(Fig.6). Surprisingly 67\% of the women are not aware of the term SAR value and also not aware of the SAR value of their mobile phone(Fig.7).

Figure 5: Bar chart representing the responses for awareness on the amount of radiation they are exposed

\section{AWARENESS OF AMOUNT OF RADIATION WOMEN ARE EXPOSED}
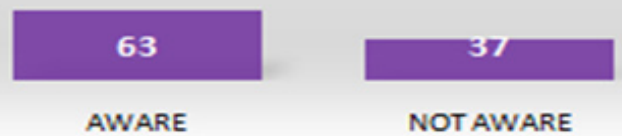

Figure 6: Bar chart representing the responses for harmful effects of radiation to foetus

\section{EFFECTS OF RADIATION TO FOETUS}

FOETUS
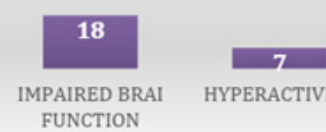

HYPERACTIVITY FUNCTION

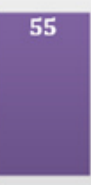

ALL THE ABOVE
Specific absorption rate (SAR) is a measure of the rate of radiofrequency (RF) energy absorption by the body from the source being measured, i.e., cell phone in this case. While SAR values serve as an important tool in judging the maximum possible exposure to RF energy, a single SAR value will not provide sufficient information concerning the amount of RF exposure under regular usage conditions to reliably compare different cell phone models (Bhoil, Kumar and Bhoil, 2015). 33\% of the women are aware of it. The ways in which pregnant women can avoid radiation were assessed. They are usage of telephone instead of mobile, switch off WiFi when not in use, avoid carrying mobile in pocket etc.

Figure 7: Bar chart representing the responses for awareness on SAR value.

\section{AWARENESS OF SAR VALUE}

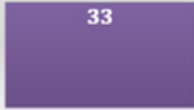

AWARE

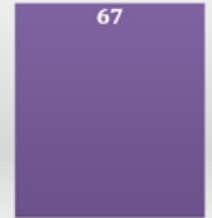

NOT AWARE
Many studies show that exposure to mobile phones before and after birth may increase a child's risk for developing certain behavioral problems, including hyperactivity, inattention, and problems getting along with peers. But in a Spanish birth cohort study researchers found no associations between maternal cell phone use during pregnancy and child's early mental development (Vrijheid et al., 2010). However excessive exposure to radiation from gadgets may harm the foetus and the mother too. So it's better to prevent and minimise the use of gadgets during the period of pregnancy for a safer aspect.

\section{CONCLUSION}

From this study, we conclude that most of the women are not aware of the effects of radiation emitted from electronic gadgets during pregnancy. Pregnancy poses special considerations in regard to radiation exposure. Exposure to EMF is found to be increasingly common, but its potential influence on human health has not been thoroughly studied, especially in pregnant women. Yet there is no conclusive evidence to justify that the use of a mobile phone or other gadgets during pregnancy is hazardous. There is limited information available on the association between EMF exposure during pregnancy and reproductive outcomes. But very high exposure to radiation may cause a harmful effect on foetus. However, it is best to be sensible during pregnancy.

\section{ACKNOWLEDGEMENTS}

The authors are thankful to Saveetha Dental College for providing a platform to express their knowledge. 
Conflict Of Interest: The authors declare no conflict of interest.

\section{REFERENCES}

Abad, M. et al. (2016) 'Association between electromagnetic field exposure and abortion in pregnant women living in Tehran', International Journal of Reproductive BioMedicine, pp. 347-354. doi: 10.29252/ ijrm.14.5.347.

Aldad, T. S. et al. (2012) 'Fetal Radiofrequency Radiation Exposure From 800-1900 Mhz-Rated Cellular Telephones Affects Neurodevelopment and Behavior in Mice', Scientific Reports. doi: 10.1038/srep00312.

Bhoil, R., Kumar, A. and Bhoil, R. (2015) 'Cell Phones and SAR Value', Indian Journal of Public Health, p. 323. doi: 10.4103/0019-557x.169671.

Brent, R. L. (1999) 'Reproductive and teratologic effects of low-frequency electromagnetic fields: a review of in vivo and in vitro studies using animal models', Teratology, 59(4), pp. 261-286.

Divan, H. A. et al. (2008) 'Prenatal and Postnatal Exposure to Cell Phone Use and Behavioral Problems in Children', Epidemiology, pp. 523-529. doi: 10.1097/ ede.0b013e318175dd47.

Haghani, M., Shabani, M. and Moazzami, K. (2013) 'Maternal mobile phone exposure adversely affects the electrophysiological properties of Purkinje neurons in rat offspring', Neuroscience, pp. 588-598. doi: 10.1016/j. neuroscience.2013.07.049.

Li, D.-K. et al. (2002) 'A population-based prospective cohort study of personal exposure to magnetic fields during pregnancy and the risk of miscarriage', Epidemiology , 13(1), pp. 9-20.

Repacholi, M. H. (2001) 'Health risks from the use of mobile phones', Toxicology Letters, pp. 323-331. doi: 10.1016/s0378-4274(01)00285-5.

Sambucci, M. et al. (2010) 'Prenatal Exposure to Non-ionizing Radiation: Effects of WiFi Signals on Pregnancy Outcome, Peripheral B-Cell Compartment and Antibody Production', Radiation Research, pp. 732-740. doi: 10.1667/rr2255.1.

Smith, A. (2010) Americans and their gadgets. Pew Internet $C$ American Life Project.

Toropainen, A. (2003) 'Human exposure by mobile phones in enclosed areas', Bioelectromagnetics, pp. 63-65. doi: 10.1002/bem. 10087.

Tsarna, E. et al. (2019) 'Associations of Maternal CellPhone Use During Pregnancy With Pregnancy Duration and Fetal Growth in 4 Birth Cohorts', American journal of epidemiology, 188(7), pp. 1270-1280.

Vrijheid, M. et al. (2010) 'Prenatal Exposure to Cell Phone Use and Neurodevelopment at 14 Months', Epidemiology, pp. 259-262. doi: 10.1097/ede.0b013e3181cb41e0.

Zhang, Y. et al. (2015) 'Effects of fetal microwave radiation exposure on offspring behavior in mice', Journal of radiation research, 56(2), pp. 261-268. 